・方法・

\title{
草原模式植物群落监测方法应用样例
}

\author{
高趁光 $^{1,2}$ 郭 柯 ${ }^{1,2 *}$ 乔鲜果 ${ }^{1,2}$ 陆帅志 ${ }^{1,2}$ \\ 刘长成 ${ }^{1}$ 侯东杰 $^{1,2}$ 王 孜 ${ }^{1,2}$
}

1 (中国科学院植物研究所植被与环境变化国家重点实验室, 北京 100093)

2 (中国科学院大学, 北京 100049)

摘要：模式植物群落是指能够反映某种植被分类单元基本特征, 并可作为准确描述该植被类型 “标准”的典型植物 群落。草原模式植物群落监测是中国生物多样性监测与研究网络——草原/荒漠植物多样性监测网的核心内容, 已 初步确定了一套监测方法。本文应用这套方法分别建立了克氏针茅(Stipa krylovii)群系和百里香(Thymus mongolicus)群系模式植物群落监测固定样地, 作为中国生物多样性监测与研究网络——草原/荒漠植物多样性监测网的样 例。介绍了这两个模式植物群落监测样地选取与设置的过程、群落调查方法和数据分析结果。通过实际观测和案 例分析, 验证了“中国草原/荒漠植物多样性监测网模式植物群落监测方案” 中监测方法的可行性, 同时根据监测中 出现的问题, 提出了模式植物群落样地、监测频率和监测日期的选择原则, 以及监测过程中的操作规范等, 完善了 模式植物群落监测内容、方法和指标体系的建议, 为开展草原模式植物群落监测提供了可借鉴的实例与技术储备。 关键词：模式植物群落; 克氏针茅草原; 百里香草原; 监测方法

\section{Methods of observing typical steppe plant communities: Applications to two typical formations}

Chenguang Gao ${ }^{1,2}$, Ke Guo ${ }^{1,2 *}$, Xianguo Qiao ${ }^{1,2}$, Shuaizhi Lu ${ }^{1,2}$, Changcheng $\mathrm{Liu}^{1}$, Dongjie Hou ${ }^{1,2}$, Zi Wang ${ }^{1,2}$ 1 State Key Laboratory of Vegetation and Environmental Change, Institute of Botany, Chinese Academy of Sciences, Beijing 100093

2 University of Chinese Academy of Sciences, Beijing 100049

\begin{abstract}
A typical plant community, which reflects the basic community characteristics of a vegetation classification unit, can be designated as a standard unit for describing a distinct vegetation type. Providing observations of typical plant communities in the steppe is the main function of the Steppe and Desert Biodiversity Observation Network and Sino Biodiversity Observation Network (Sino BON). Methods of observing typical plant communities have been published. We set up permanent observation plots of Form. Stipa krylovii and Form. Thymus mongolicus as examples during the summer of 2017. Observation methods were applied and validated, and included stand selection and plot design, vegetation surveys, and data analysis. Based on practical observations and analysis, we demonstrated the applicability of the observation methods presented in the previously published paper "Methods of observing typical plant communities in the Steppe and Desert Biodiversity Observation Network, Sino BON". Suggestions for the improvement of the content, methods, and indices of observation were presented with respect to problem areas. We aim to provide a case demonstrating the applicability of the standard methods for future observations.
\end{abstract}

Key words: typical plant community; Form. Stipa krylovii; Form. Thymus mongolicus; observation methods

生物多样性因人类活动干扰的不断加剧和全 球变化的影响正面临快速丧失的威胁(Hooper et al,
2005)。保护生物多样性已成为全人类的共识，联合 国和各国政府也都给予高度重视，并在达成《生物

收稿日期: 2017-12-15; 接受日期: 2018-03-18

基金项目: 国家重点基础研究发展计划(973 计划) (2014CB-138800)和科技基础性工作专项(2015FY210200)

* 通讯作者 Author for correspondence. E-mail: guoke@ibcas.ac.cn 
多样性公约》的基础上不断推进一系列新的保护计 划和行动(Tittensor et al, 2014)。我国政府自1992年 签订《生物多样性公约》以来, 制定了一系列生物 多样性保护法律法规和行动规划, 学术界开展了大 量生物多样性调查、物种编目、物种生存状况评估、 濒危物种保护等基础性工作, 为履约做出了巨大 贡献。

2010年9月15日，国务院第126次常务会议审议 通过并发布实施《中国生物多样性保护战略与行动 计划》, 将 “开展生物多样性调查、评估与监测” 作 为优先领域, 同时“生物多样性监测网络建设与示 范工程” 也被列为亟需实施的项目之一(薛达元, 2011)。与此同时, 《生物多样性公约》缔约方召开 了第十次大会, 为未来十年全球生物多样性保护确 立了“立即采取有效措施，遏制生物多样性丧失”的 目标(马克平, 2011)。中国科学院于 “十二五” 期间组 建了中国生物多样性监测与研究网络(Sino Biodiversity Observation Network, Sino BON) (马克平, 2015), 随后又在 “十三五” 期间加大投入力度, 购置 网络监测的硬件设备, 完善管理体系和专业技术力 量, 以提高生物多样性监测与研究能力。

中国草原/荒漠植物多样性监测网(Steppe \& Desert Biodiversity Observation Network of Sino BON)作为其中的一个专项网, 旨在从生态系统的 角度出发, 以植被群系为监测的基本单元, 在以草 原/荒漠植被为主要群系的典型地段上建立模式植 物群落监测固定样地, 应用统一的方法和规范, 长 期监测其植物多样性的变化(马克平，2015)。其中, 模式植物群落是指能够反映某种植被分类单元基 本特征, 并可作为准确描述该植被类型的典型植物 群落。模式植物群落监测是中国草原/荒漠植物多样 性监测网的一项重要内容(郭柯等, 2016)。

克氏针茅(Stipa krylovii)是禾本科针茅属植物 (Nobis et al, 2016)。克氏针茅草原是欧亚草原区东 部草原亚区分布最广的丛生禾草典型草原群系之 一, 在蒙古高原草原地带, 尤其在我国呼伦贝尔草 原和锡林郭勒草原有大面积的连续分布。百里香 (Thymus mongolicus)是唇形科百里香属植物。百里 香草原是小半灌木典型草原中的主要群系之一, 亦 在欧亚草原区东部草原亚区以及向森林地带毗邻 的过渡区域广泛分布, 在西辽河上游的黄土丘陵地 区、鄂尔多斯高原东部及晋陕宁甘黄土高原草原地
带尤为常见, 是表土侵蚀严重的草原上具有很强代 表性的次生群落类型(吴征镒, 1980; 中国科学院内 蒙古宁夏综合考察队, 1985; 陈灵芝等, 2014)。

本文根据“中国草原/荒漠植物多样性监测网模 式植物群落监测方案” (郭柯等, 2016)中的主要监测 内容、方法和指标, 选择克氏针茅草原和百里香草 原模式植物群落为监测样例, 开展了首期实地调查, 并对所得数据进行了初步的分析和报道。目的在于: (1)验证“中国草原/荒漠植物多样性监测网模式植物 群落监测方案” 中监测方法的可行性; (2)探索完善 模式植物群落监测的内容、方法和指标体系的具体 途径; (3)为开展草原模式植物群落监测提供可借鉴 的实例与技术方法。

\section{克氏针茅群系模式植物群落监涉}

\section{1 样地选择}

参考《中国植被》(吴征镒，1980)、《内蒙古植 被》(中国科学院内蒙古宁夏综合考察队, 1985)和 《中华人民共和国植被图》(中国科学院中国植被图 编辑委员会，2007)等相关资料，并根据“中国草原/ 荒漠植物多样性监测网模式植物群落监测方案” (郭柯等, 2016)中的样地设置原则选择监测样地。主 要考虑的因素有: (1)地形特点, 具体的地形主要选 择地势相对平缓、开阔的地带, 应保证地形一致性 高, 避免较大起伏; (2) 土地利用与人为干扰状况, 主要依据植物群落退化程度、样地所在区域牲畜粪 便密集程度和人为活动痕迹密度等因素来确定; (3) 植被变迁历史, 主要通过走访询问样地附近牧民来 获取样地利用历史, 作为判断植被变迁历史的主要 依据。2017年6月, 经过实地调查和反复对比, 确认 中国农业科学院太仆寺旗草地资源生态监测与评 价野外科学观测试验站西小山丘中上部的克氏针 茅草原具有典型性(即群落建群种克氏针茅重要值 占据显著优势), 在此设置了主、副两个模式植物群 落监测样地。

\section{2 样地设置与信息收集}

克氏针茅群系模式植物群落主样地中心点地 理坐标为 $115^{\circ} 14^{\prime} 17.76^{\prime \prime} \mathrm{E}, 41^{\circ} 49^{\prime} 49.02^{\prime \prime} \mathrm{N}$, 海拔 $1,463 \mathrm{~m}$; 副样地中心点地理坐标为 $115^{\circ} 14^{\prime} 49.56^{\prime \prime} \mathrm{E}$, $41^{\circ} 49^{\prime} 49.56^{\prime \prime} \mathrm{N}$, 海拔1,484 m。主、副样地分别位于 丘坡中部和近顶部, 相距约 $400 \mathrm{~m}$, 高差 $21 \mathrm{~m}$ 。

根据 $\mathrm{Ni}$ 等(2000)插值气象数据, 样地年均气温 
$2.78^{\circ} \mathrm{C}$, 最热月平均气温 $18.30^{\circ} \mathrm{C}$, 最冷月平均气温 $-17.40^{\circ} \mathrm{C}$; 年均降水量383.52 $\mathrm{mm}$, 主要集中在夏秋 季, 冬春季降水稀少, 其中最热月降水量 $97.65 \mathrm{~mm}$, 占全年降水量的 $25.46 \%$ 。样地具沙壤质栗钙土。样 地附近的草原目前主要作为草地观光旅游活动场 地, 有轻度放牧, 根据家畜粪迹判定为羊马混牧, 主样地 $20 \mathrm{~m} \times 20 \mathrm{~m}$ 面积内有鼠洞 4 个。

首先, 确定样地中心点 $\mathrm{O}$, 记录其地理坐标; 其次, 以此为参照点, 用罗盘和卷尺找出东西南北 4 个方向距中心点 $5 \mathrm{~m}$ 和 $10 \mathrm{~m}$ 处位置, 再确定通过这 些点的 $10 \mathrm{~m} \times 10 \mathrm{~m}$ 正方形样地核心区和 $20 \mathrm{~m} \times 20$ $\mathrm{m}$ 的外围 $10 \mathrm{~m}$ 宽样地缓冲区边界; 再次, 在样地核 心区和缓冲区四角置入长度 $30 \mathrm{~cm}$ 的钢筋界桩, 至 露出地表 $0.5 \mathrm{~cm}$ 左右, 并记录地理坐标参数, 保证 样地的精确定位和今后复查参考; 最后, 拍摄样地 及植物群落外貌的宏观照片(附录1)。

调查样方设置, 在样地中心点及该点正北、正 东、正南、正西分别设置 5 个 $1 \mathrm{~m} \times 1 \mathrm{~m}$ 的样方, 并标 记为 $\mathrm{Q} 1 、 \mathrm{Q} 2 、 \mathrm{Q} 3 、 \mathrm{Q} 4$ 和 $\mathrm{Q} 5$, 后4个样方距中心点和 核心区的边界为 $2 \mathrm{~m}$, 这 5 个样方作为长期群落学监 测的固定样方; 随后在缓冲区距离核心区边界 $1 \mathrm{~m}$ 处选择3个 $1 \mathrm{~m} \times 1 \mathrm{~m}$ 的样方, 分别标记为Q6、Q7和 Q8, 除进行同样的群落学调查外, 还通过齐地面刚 割法收集地上生物量(图1)。

\section{3 群落特征调查与数据处理}

在设置好的样地内开展物种踏查, 记录出现的 所有物种。标本采集原则上在样地缓冲区外进行, 采集样地中每个物种的标本并注明采集日期和标 本号。由于样地调查时间较早, 部分植物尚未开花 结果, 可采集往年枯枝等作为补充。用相机记录每 个物种的生境照片。标本带回实验室后认真对比鉴 定, 确保鉴定正确。采集到的样地植物标本作为模 式植物群落监测样地物种组成的凭证永久保存。

模式植物群落样地的土壤特征调查选择在样 地缓冲区内进行, 挖取50 $\mathrm{cm}$ 深土壤剖面(副样地下 伏岩石, 剖面深度为 $30 \mathrm{~cm}$ ), 观察并拍照记录土壤 剖面及根系分布特征。两个样地都显示, 植物根系 主要集中在0-10 $\mathrm{cm}$ 的表土层, 各层土壤结构较均 匀, 主样地的土壤较副样地更为疏松。然后在土壤 剖面上按照从下到上的顺序分层取样, 土样带回实 验室风干，测定 $\mathrm{pH}$ 、有机碳、全氮、全磷、有效氮 和有效磷等(表1)。详细的土壤剖面特征见附录2。

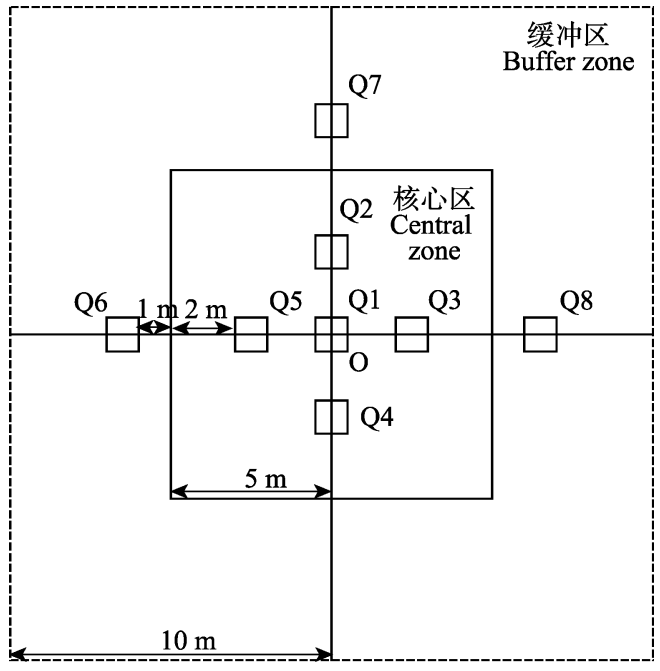

图1 克氏针茅群系模式植物群落样地设置。Q: 样方, $1 \mathrm{~m} \times$ $1 \mathrm{~m}$; O: 样地中心点。

Fig. 1 Plot design of typical plant community of Form. Stipa krylovii. Q, Quadrats, $1 \mathrm{~m} \times 1 \mathrm{~m}$; O, Central point of the plot.

模式植物群落样地内的样方调查项目包括各 物种的个体数量、营养枝高度及生殖枝高度、物种 盖度及群落的总盖度。此外, 缓冲区内的 3 个样方选 择齐地面刚割法分物种收获地上生物量，并带回实 验室 $65^{\circ} \mathrm{C}$ 烘干至恒重，用电子天平(精度 $0.01 \mathrm{~g}$ )称取 干重, 最后基于各物种生物量数据计算出群落生物量。

\section{4 群落特征}

\subsection{1 物种组成}

根据获得的数据, 计算群落的Shannon-Wiener 多样性指数 $\left(H^{\prime}\right)$ 和Pielou均匀度指数 $(J)$, 公式如下:

$$
\begin{aligned}
& H^{\prime}=-\sum P_{i} \ln P_{i} \\
& H_{\text {max }}^{\prime}=\ln S \\
& J=H^{\prime} / H_{\text {max }}^{\prime}
\end{aligned}
$$

式中, $S$ 是群落总物种数, $H_{\max }^{\prime}$ 是最大均匀条件下的 Shannon-Wiener多样性指数, $P_{i}$ 为物种 $i$ 占全部物种 重要值的比例。

物种的重要值采用公式 “ $I V=($ 相对盖度 + 相对 高度+相对生物量+相对多度)/4”计算, 在生物量缺 失的样方中, 采用公式“ $I V=($ 相对盖度 + 相对高度 + 相对多度)/3”计算。

克氏针茅群系模式植物群落两个样地的物种 平均丰富度为 17.5 种 $/ \mathrm{m}^{2}$, Shannon-Wiener指数为 2.78 , Pielou均匀度指数为 0.69 。

克氏针茅群系模式植物群落两个样地共记录 到植物 57 种, 隶属于 22 科 45 属。其中, 主样地记录 40 种, 隶属于19科33属, 物种较多的科依次是菊科 
表1 克氏针茅群系模式植物群落土壤理化性状

Table 1 Basic properties of typical plant community of Form. Stipa krylovii

\begin{tabular}{|c|c|c|c|c|c|c|c|c|}
\hline & & & 主样地 Mai & plot & & & 样地 Auxil & ry plot \\
\hline & $0-10 \mathrm{~cm}$ & $10-20 \mathrm{~cm}$ & $20-30 \mathrm{~cm}$ & $30-40 \mathrm{~cm}$ & $40-50 \mathrm{~cm}$ & $0-10 \mathrm{~cm}$ & $10-20 \mathrm{~cm}$ & $20-30 \mathrm{~cm}$ \\
\hline $\mathrm{pH}$ & 7.84 & 8.23 & 8.35 & 8.88 & 8.82 & 8.05 & 8.11 & 8.38 \\
\hline 有机碳 Organic carbon (g/kg) & 25.14 & 17.13 & 10.25 & 10.67 & 6.52 & 26.87 & 42.64 & 42.92 \\
\hline 全氮 Total N (g/kg) & 2.46 & 1.66 & 1.00 & 1.14 & 0.68 & 2.60 & 4.03 & 3.92 \\
\hline 全磷 Total P (g/kg) & 25.14 & 17.13 & 10.25 & 0.29 & 0.23 & 0.46 & 0.47 & 0.42 \\
\hline 有效氮 Available N (mg/kg) & 190.25 & 112.25 & 72.29 & 13.25 & 8.97 & 262.54 & 177.88 & 89.42 \\
\hline 有效磷 Available P (mg/kg) & 6.30 & 3.40 & 3.40 & 2.20 & 2.20 & 5.00 & 6.10 & 4.00 \\
\hline
\end{tabular}

(7属8种)、禾本科(7属7种)、豆科(3属4种)、蓄薇科 (1属3种)、报春花科(1属2种)、龙胆科(1属2种)和感 尾科(1属2种), 其余的车前科、唇形科、景天科、藜 科、毛茛科、瑞香科、伞形科、莎草科、石竹科、 远志科、芸香科和紫草科等12科各含 1 个物种。副 样地共记录到植物 31 种, 隶属于15科 27 属, 物种较 多的科有蓄微科(3属6种)、禾本科(5属5种)、菊科 (4 属5种)、豆科(2属2种)、十字花科(2属2种)、石竹科 (2属2种), 剩下的百合科、报春花科、唇形科、龙胆 科、伞形科、莎草科、玄参科、芸香科和紫草科等 9 科各含 1 个物种。两个样地共有种有克氏针茅、䊁 隐子草(Cleistogenes squarrosa)、硬质早熟禾(Poa sphondylodes)、冷蒿(Artemisia frigida)等14个物种。

根据《中国植被》中的生活型分类法, 克氏针 茅群系模式群落中的57种植物可划分为半灌木和 小半灌木、多年生禾草和薹草、多年生杂类草和一、 二年生草本植物 4 类生活型。其中, 多年生杂类草最 多, 占总数的 $63.16 \%$; 其次是一、二年生草本植物, 占总数的 $15.79 \%$; 多年生禾草和臺草占总数的 $14.03 \%$; 半灌木和小半灌木占总数的 $7.02 \%$ (图2)。

通过查阅相关资料(中国科学院中国植物志编 辑委员会, 2004; 赵一之, 2012), 并根据植物对水分 因子的适应性特征, 57种植物可以划分为典型早生 植物、中旱生植物、广旱生植物、旱中生植物和典 型中生植物 5 种水分类型。典型旱生植物种类最多, 占 $45.62 \%$; 其次是中旱生植物和典型中生植物, 分 别占 $21.05 \%$; 旱中生植物占 $7.02 \%$; 广旱生植物占 $5.26 \%$ (图3)。水分生态类型谱反映了克氏针茅群系 模式植物群落的旱生性特点。

依据相关的资料以及对物种分布区的分析(中 国科学院中国植物志编辑委员会, 2004; 赵一之, 2012), 可将克氏针茅群系模式植物群落的植物区
系地理成分归纳为6类(图4)。其中，东古北极成分最 多，占47.37\%; 其次是东亚成分，占 $22.81 \%$; 泛北 极成分占 $10.52 \%$; 中亚-亚洲中部成分占 $8.77 \%$; 亚 洲中部成分占7.02\%; 古北极成分占3.51\%。

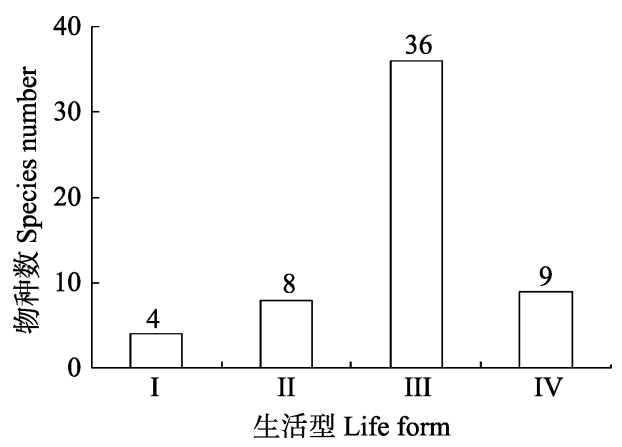

图2 克氏针茅群系模式植物群落物种的生活型谱。I: 半灌 木和小半灌木; II: 多年生禾草和臺草; III: 多年生杂类草; IV: 一、二年生草本植物。

Fig. 2 Life form spectrum of the species in typical plant community of Form. Stipa krylovii. I, Semi-shrub and dwarf semi-shrub; II, Perennial grasses and sedges; III, Perennial forbs; IV, Annuals and biennials.

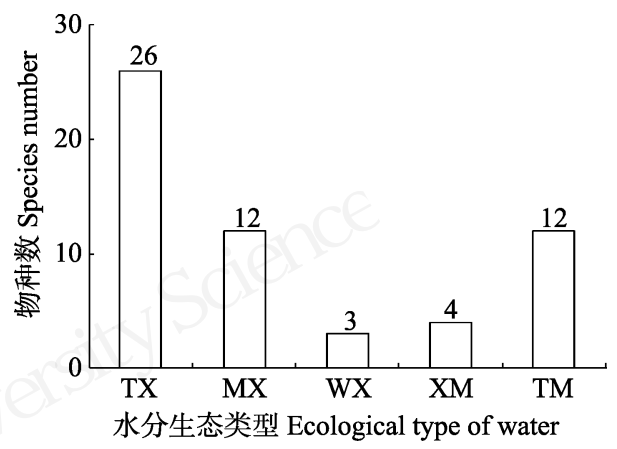

图3 克氏针茅群系模式植物群落物种的水分生态类型谱。

$\mathrm{TX}$ : 典型旱生植物; MX: 中旱生植物; WX: 广旱生植物; XM: 旱中生植物; TM: 典型中生植物。

Fig. 3 Ecological type of water of the species in typical plant community of Form. Stipa krylovii. TX, Typical xerophytes; MX, Meso-xerophytes; WX, Wide xerophytes; XM, Xero-mesophytes; TM, Typical mesophytes. 


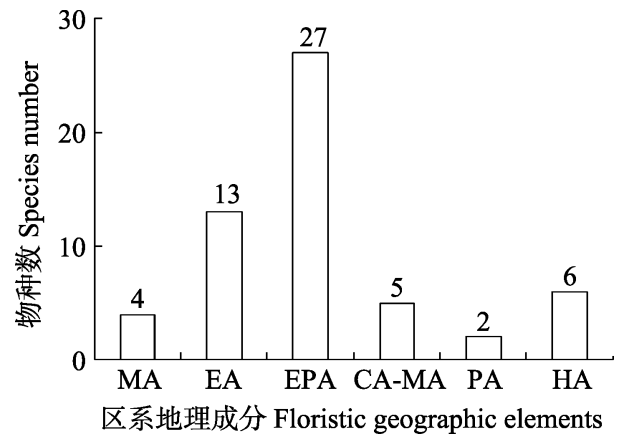

图4 克氏针茅群系模式植物群落物种区系地理成分组成。 MA: 亚洲中部成分; EA: 东亚成分; EPA: 东古北极成分; CA-MA: 中亚-亚洲中部成分; PA: 古北极成分; HA: 泛北 极成分。

Fig. 4 Floristic geographic distribution of the species in typical plant community of Form. Stipa krylovii. MA, Middle Asia element; EA, East Asia element; EPA, East Palaearctic element; CA-MA, Central Asia-Middle Asia element; PA, Palaearctic element; HA, Holarctic element.

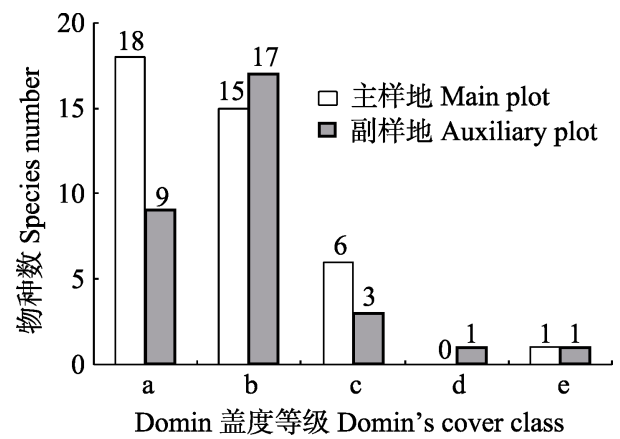

图5 克氏针茅群系模式植物群落物种的Domin盖度等级分 布。a: 1级盖度 $(0.1 \%)$; b: 2级盖度 $(0.1-1 \%) ; \mathrm{c}$ ：3级盖度 (1-4\%); d: 4级盖度(5-10\%); e: 5级盖度(11-25\%)。

Fig. 5 Domin's cover class distribution of the species in typical plant community of Form. Stipa krylovii. a, Cover class 1 (0.1\%); b, Cover class 2 (0.1-1\%); c, Cover class 3 (1-4\%); d, Cover class 4 (5-10\%); e, Cover class 5 (11-25\%).

\subsection{2 盖度}

根据调查样方的记录, 克氏针茅群系模式植物 群落的平均盖度为 $26.29 \%$, 最小 $17.10 \%$, 最大 $34.80 \%$ 。将克氏针茅主、副两个样地内各物种分盖 度分别按照Domin盖度等级(张金屯, 2011)划分为5 个等级(图5), 可以看到以 $1 、 2$ 级盖度为主, 多为偶见 种或伴生种; 两个样地的 5 级盖度植物都只有克氏针 茅一种, 平均盖度为 $11.40 \%$, 在群落中占绝对优势。

\subsection{3 生物量和群落结构}

克氏针茅群系模式植物群落样地的地上生物 量平均为 $159.34 \mathrm{~g} / \mathrm{m}^{2}$, 最小 $137.21 \mathrm{~g} / \mathrm{m}^{2}$, 最大为 $181.38 \mathrm{~g} / \mathrm{m}^{2}$ 。

植物群落垂直结构大致可以分为三层: 第一层
高度在20-30 cm之间，主要是建群种克氏针茅和一 些高大杂类草; 第二层为粘隐子草和大多数的杂类 草，高度为5-20 cm; 最下层为小半灌木冷蒿和一 些匍匐、垫状的植物。由于调查时间在生长季早期, 大部分植物高度在生长季中后期还会有一定变化。

\section{5 模式植物群落信息档案建立}

将以上获得的环境、群落调查数据和影像资料 统一汇总备份, 建立克氏针茅群系模式植物群落信 息档案。信息档案主要分为两大项，包括物种资料 信息(标本实物和标本照片)和群落信息(群落地理 位置、环境信息、群落照片、群落季相特点、群落 结构)。建成的信息档案明确标注档案建立人、建立 日期等详细内容，以便于后期分析利用。

\section{百里香群系模式植物群落监测}

\section{1 群落样地选择}

百里香草原是以唇形科小半灌木百里香为建 群种的典型草原，对风蚀和表土侵蚀有很强的适应 性。参考《中国植被》(吴征镒，1980)、《内蒙古植 被》(中国科学院内蒙古宁夏综合考察队，1985)和 《中华人民共和国植被图》(中国科学院中国植被图 编辑委员会, 2007)等相关资料, 采用类似克氏针茅 草原模式植物群落监测样地的选择方法，于2017年 6 月 15 日选定康保县满堂红乡变电站东山丘坡顶的 百里香草原作为百里香群系模式植物群落监测主 样地 $\left(114^{\circ} 28^{\prime} 36.04^{\prime \prime}\right.$ E, 4150 $50^{\prime} 37.23^{\prime \prime} \mathrm{N}$, 海拔1,546 m) (附录1)。根据 $\mathrm{Ni}$ 等(2000)插值气象数据, 样地年均 气温 $3.02^{\circ} \mathrm{C}$, 最热月平均气温 $18.60^{\circ} \mathrm{C}$, 最冷月平均 气温 $-17.00^{\circ} \mathrm{C}$; 年均降水量353.06 mm, 主要集中在 夏秋季，冬春季降水稀少，其中最热月降水量95.02 $\mathrm{mm}$ ，占全年降水量的 $26.91 \%$ 。样地所在草原有放牧 活动, 地表有大量碎石, 土壤为砂壤质, 挖取的土 壤剖面深度为 $40 \mathrm{~cm}$, 各层土壤中均含有大量碎石, 植物根系主要集中在 $0-20 \mathrm{~cm}$ 的土层。

百里香群系模式植物群落副样地位于内蒙古 自治区多伦县淖尔镇水泉村 $\left(116^{\circ} 24^{\prime} 43.79^{\prime \prime} \mathrm{E}\right.$, $42^{\circ} 12^{\prime} 03.26^{\prime \prime} \mathrm{N}$ ，海拔1,314 m)。根居 Ni等(2000)插值 气象数据, 样地的年均气温 $1.65^{\circ} \mathrm{C}$, 最热月平均气 温 $18.69^{\circ} \mathrm{C}$, 最冷月平均气温 $-18.12^{\circ} \mathrm{C}$; 年均降水量 $390.08 \mathrm{~mm}$, 降水主要集中在夏秋季, 冬春季降水 稀少，其中最热月降水量99.60 mm，占全年降水量 $25.53 \%$ 。样地位于山坡中上部，山坡一侧有人工种 
表2 百里香群系模式植物群落样地土壤理化性状

Table 2 Basic properties of typical plant community of Form. Thymus mongolicus

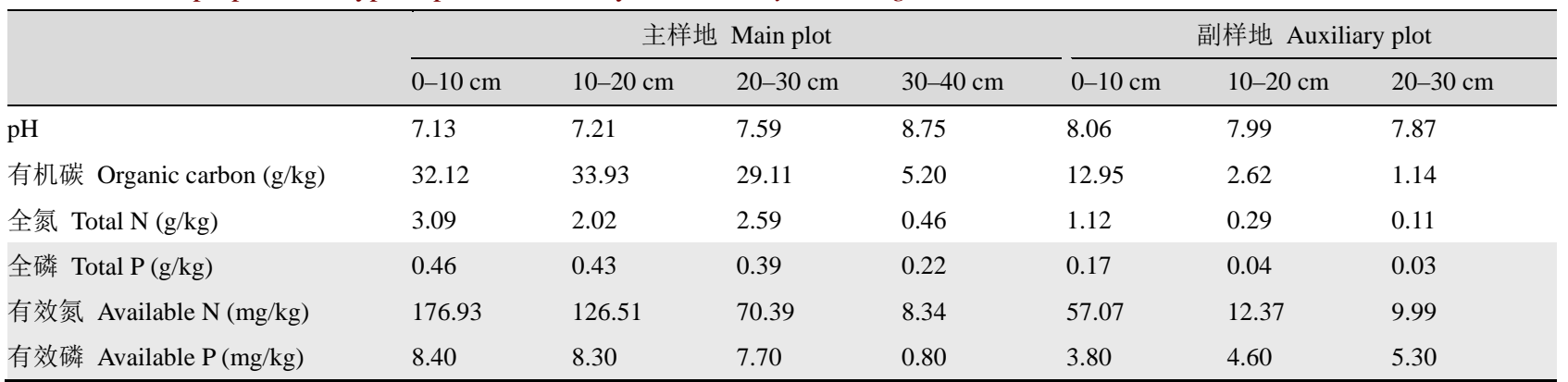

植的樟子松(Pinus sylvestris var. mongolica)。副样地 土壤质地为砂砾质, 地表可见大量碎砾石块, 植物 根系主要集中在10-20 cm土层, 详细的土壤剖面特 征见附录2。

百里香群系模式植物群落样地建设步骤、调查 与数据处理方法及指标、信息档案的建立同克氏针 茅群系模式植物群落一致。

\section{2 群落特征}

\subsection{1 物种组成}

百里香群系模式植物群落样地的物种平均丰 富度为 20.9 种 $/ \mathrm{m}^{2}$, Shannon-Wiener指数为 2.94 , Pielou均匀度指数为 0.72 。

百里香群系模式植物群落的两个样地内共记 录到59种植物, 隶属23科52属。其中主样地记录到 植物34种, 隶属于 19 科 30 属。物种较多的科有菊科 (5属6种)、禾本科(4属4种)、豆科(2属3种)、石竹科 (3属3种)。副样地共记录到植物46种, 隶属于19科42 属, 物种较多的科有菊科(10属11种)、禾本科(7属7 种)、蓄薇科(3属5种)、豆科(3属3种)。两个样地共 有种有克氏针茅、冰草(Agropyron cristatum)、䊁隐 子草、阿尔泰狗娃花(Heteropappus altaicus)、冷蒿 等21个物种。

植物生活型组成以多年生杂类草种类最为丰 富, 占总数的 $62.71 \%$; 其次是多年生禾草和薹草, 占 $15.26 \%$; 一、二年生草本植物占 $15.25 \%$; 半灌木 和小半灌木占 $6.78 \%$ (图6)。

样地中 59 种植物以典型旱生种类最多, 占 $47.46 \%$, 表明百里香草原的旱生性强; 其次是中旱 生植物和典型中生植物, 分别占 $25.42 \%$ 和 $20.34 \%$ (图7)。

植物区系地理成分组成中, 东古北极成分占 49.15\%，东亚成分占 $22.03 \%$ ，泛北极成分占 $13.56 \%$ ，

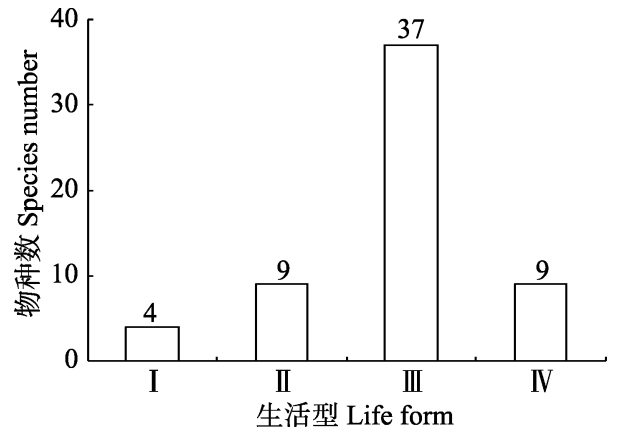

图6 百里香群系模式植物群落物种的生活型谱。I: 半灌木 和小半灌木; II: 多年生禾草和臺草; III: 多年生杂类草; IV: 一、二年生草本植物。

Fig. 6 Life form spectrum of the species in typical plant community of Form. Thymus mongolicus. I, Semi-shrub and dwarf semi-shrub; II, Perennial grass and sedge; III, Perennial forbs; IV, Annuals and biennials.

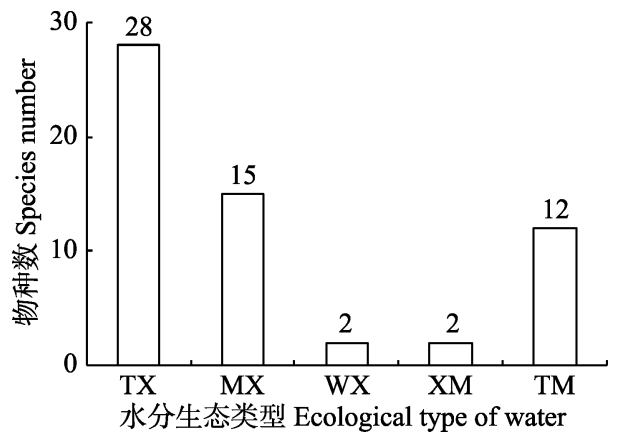

图7 百里香群系模式植物群落物种的水分生态类型谱。TX: 典型旱生植物; MX: 中旱生植物; WX: 广旱生植物; XM: 旱中生植物; TM: 典型中生植物。

Fig. 7 Ecological type of water of the species in typical plant community of Form. Thymus mongolicus. TX, Typical xerophytes; MX, Meso-xerophytes; WX, Wide xerophytes; XM, Xero-mesophytes; TM, Typical mesophytes.

中亚-亚洲中部成分占 $8.48 \%$, 亚洲中部成分和古北 极成分各占 $3.39 \%$ (图8)。

\subsection{2 盖度}

根据调查样方的记录, 百里香群系模式植物群 落平均盖度为 $28.14 \%$, 最小 $22.00 \%$, 最大 $40.20 \%$ 
(图9)。两个样地只有百里香一种分盖度较高, 在群 落中占据绝对优势, 其他物种分盖度都较低, 尤其 是群落偶见种。

\subsection{3 生物量和群落结构}

在6月13日和15日样地调查时，百里香群系模 式植物群落 2 个样地 6 个生物量测定样方的地上生 物量平均为 $102.07 \mathrm{~g} / \mathrm{m}^{2}$, 最小 $85.12 \mathrm{~g} / \mathrm{m}^{2}$, 最大为 $140.54 \mathrm{~g} / \mathrm{m}^{2}$ 。群落水平结构呈现明显的镶嵌性, 斑 块状的百里香种群和克氏针茅等植物相间分布。群 落垂直结构与生境有很大关系。主样地石质化程度 略强，相对干旱，群落较为低矮，可分为两层：第 一层由多年生丛生禾草和高大的杂类草构成, 植从

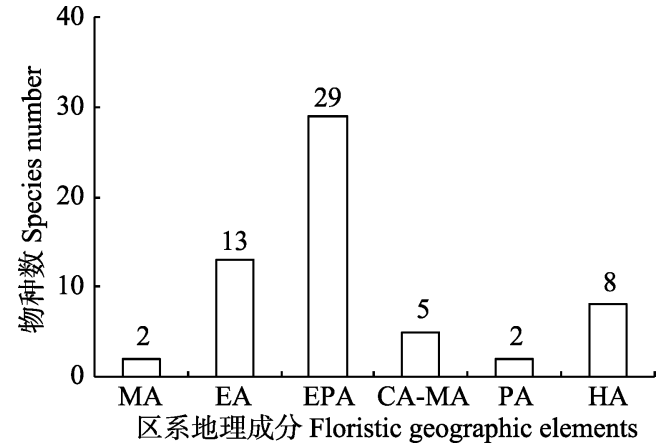

图8 百里香群系模式植物群落物种区系地理成分组成。 MA: 亚洲中部成分; EA: 东亚成分; EPA: 东古北极成分; CA-MA: 中亚-亚洲中部成分; PA: 古北极成分; HA: 泛北 极成分。

Fig. 8 Floristic geographic distribution of the species in typical plant community of Form. Thymus mongolicus. MA, Middle Asia element; EA, East Asia element; EPA, East Palaearctic element; CA-MA, Central Asia-Middle Asia element; PA, Palaearctic element; HA, Holarctic element.

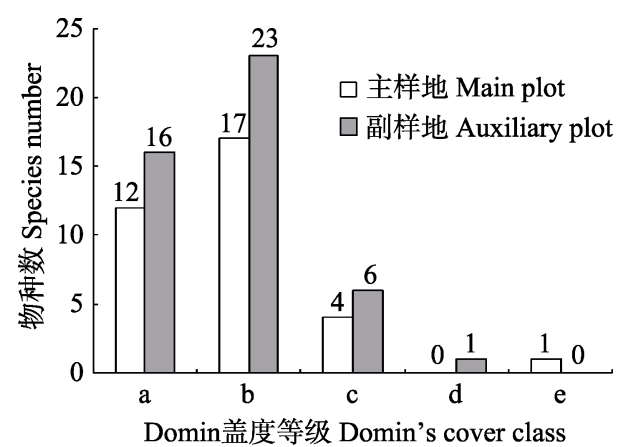

图9 百里香群系模式植物群落物种的Domin盖度等级分 布。a: 1 级盖度 $(0.1 \%) ; \mathrm{b}: 2$ 级盖度 $(0.1-1 \%) ; \mathrm{c}$ : 3 级盖度 (1-4\%); d: 4级盖度(5-10\%); e: 5级盖度(11-25\%)。

Fig. 9 Domin's cover class distribution of the species in typical plant community of Form. Thymus mongolicus. a, Cover class 1 (0.1\%); b, Cover class 2 (0.1-1\%); c, Cover class 3 (1-4\%); d, Cover class 4 (5-10\%); e, Cover class 5 (11-25\%).
稀疏；第二层由小半灌木百里香、冷蒿和多年生丛 生小禾草构成。副样地相对湿润，土壤条件略好， 群落高度较高，其垂直结构可分为三层：第一层由 克氏针茅和高大的杂类草等构成; 第二层主要由较

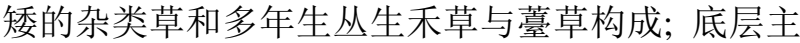
要由百里香等物种构成。

\section{3 讨论}

依据“中国草原/荒漠植物多样性监测网模式植 物群落监测方案”的监测方法和指标，我们开展了 首期模式植物群落的建设，并获得了第一批数据。 实践表明，该监测方案具有很强的可操作性，但在 具体实践过程中，仍存在一些问题。我们建议模式 植物群落监测应改善以下几方面的工作:

(1)模式植物群落样地的选择。所选样地位于草 原区，放牧、开艮等人为干扰导致的草地退化相当 严重，这给寻找合适的模式植物群落样地带来了很 大困难, 因此, 今后的草原模式植物群落样地建设 应尽量优先设置在人为活动强度较低的区域，如自 然保护区内或远离放牧点的地方。

(2)监测频率和监测日期的选择。一年一次的监 测频度难以全面揭示模式植物群落的基本情况, 特 别是群落物种组成与季相存在周期性的年度变化, 各物种的生长发育和物候变化也不完全相同, 生物 量有明显的季节变化, 如本次监测到的群落地上生 物量只能反映6月中旬前后的情况，与 8 月初群落生 物量最高峰时期会存在一定的差异。因此, 在以后 的监测中，应根据不同模式植物群落的特征和监测 目标，设置相应的监测时间和频率，一年一次的监 测也最好考虑把监测时间选择在7月底8月初。

(3)缓冲区调查样方的设置。考虑到监测样地正 方形的形状，以后模式植物群落缓冲区内获取生物 量的监测样方应在 4 个方向各设置 1 个，以更加全面 记录缓冲区内群落特征并方便后期的复查。

(4)样方内物种数目的记录。在模式植物群落样 方调查中，植物个体计数因植物种类不同而有所区 别，不同的植物应根据具体特征区别对待(王炜等, 2000)。冷蒿、百里香等以匍匐枝相连的个体作为一 个个体; 克氏针茅、糙隐子草等丛生禾草均以植从 为单位; 星毛委陵菜(Potentilla acaulis)等斑块状聚 集的物种以株为单位; 羊草(Leymus chinensis)等根 茎型禾草以地上枝为单位。 


\section{参考文献}

Chen LZ, Sun H, Guo K (2014) Floristic and Vegetation Geography of China. Science Press, Beijing. (in Chinese) [陈 灵芝, 孙航, 郭柯 (2014) 中国植物区系与植被地理. 科 学出版社, 北京.]

Editorial Board of the Vegetation Atlas of China, Chinese Academy of Sciences (2007) 1:1000000 Vegetation Atlas of China. Geology Publishing House, Beijing. (in Chinese) [中 国科学院中国植被图编辑委员会 (2007) 中华人民共和 植被图(1:1000000). 地质出版社, 北京.]

Editorial Committee of Flora Reipublicae Popularis Sinicae (1959-2004) Flora Republicae Popularis Sinicae. Science Press, Beijing. (in Chinese) [中国科学院中国植物志编辑 委员会 (1959-2004) 中国植物志. 科学出版社, 北京.]

Guo K, Liu CC, Pan QM (2016) Methods of observing typical plant communities in the Steppe and Desert Biodiversity Observation Network, Sino BON. Biodiversity Science, 24, 1220-1226. (in Chinese with English abstract) [郭柯, 刘长 成, 潘庆民 (2016) 中国草原/荒漠植物多样性监测网模 式植物群落监测方案. 生物多样性, 24, 1220-1226.]

Hooper DU, Chapin FS III, Ewel JJ, Hector A, Inchausti P, Lavorel S, Lawton JH, Lodge DM, Loreau M, Naeem S (2005) Effects of biodiversity on ecosystem functioning: A consensus of current knowledge. Ecological Monographs, 75, 3-35.

Inner Mongolia and Ningxia Scientific Expedition Group, Chinese Academy of Sciences (1985) Vegetation of Inner Mongolia. Science Press, Beijing. (in Chinese) [中国科学院 内蒙古宁夏综合考察队 (1985) 内蒙古植被. 科学出版 社, 北京.]

Ma KP (2011) Strategic targets for biodiversity conservation in 2011-2020. Biodiversity Science, 19, 1-2. (in Chinese) [马 克平 (2011) 未来十年的生物多样性保护目标. 生物多 样性, 19, 1-2.]

Ma KP (2015) Biodiversity monitoring in China: From CForBio to Sino BON. Biodiversity Science, 23, 1-2. (in Chinese) [马克平 (2015) 中国生物多样性监测网络建设: 从CForBio到Sino BON. 生物多样性, 23, 1-2.]

Ni J, Sykes MT, Prentice IC, Cramer W (2000) Modeling the vegetation of China using the process-based equilibrium terrestrial biosphere model BIOME3. Global Ecology and Biogeography, 9, 463-479.

Nobis M, Nowak A, Piwowarczyk R, Ebel AL, Király G, Kushunina M, Sukhorukov AP, Chernova OD, Kipriyanova LM, Paszko B, Seregin AP, Zalewska-Gałosz J, Denysenko M, Nejfeld P, Stebel A, Gudkova PD (2016) Contribution to the flora of Asian and European countries: New national and regional vascular plant records, 5. Botany Letters, 163, 159-174.

Tittensor Derek P, Walpole Matt, Hill Samantha LL, Boyce Daniel G, Britten Gregory L, Burgess Neil D, Butchart Stuart HM, Leadley Paul W, Regan Eugenie C, Alkemade Rob (2014) A mid-term analysis of progress toward international biodiversity targets. Science, 346, 241-244.

Wang W, Liang CZ, Liu ZL, Hao DY (2000) Analysis of the plant individual behavior during the degradation and restoring succession in steppe community. Acta Phytoecologica Sinica, 24, 268-274. (in Chinese with English abstract) [王 炜, 梁存柱, 刘钟龄, 郝敦元 (2000) 草原群落退化与恢 复演替中的植物个体行为分析. 植物生态学报, 24, 268-274.]

Wu ZY (1980) Vegetation of China. Science Press, Beijing. (in Chinese) [吴征镒 (1980) 中国植被. 科学出版社, 北京.]

Xue DY (2011) The main content and implementation strategy for China Biodiversity Conservation Strategy and Action Plan. Biodiversity Science, 19, 387-388. (in Chinese) [薛达 元 (2011) 《中国生物多样性保护战略与行动计划》的核 心内容与实施战略. 生物多样性, 19, 387-388.]

Zhang JT (2011) Quantitative Ecology. Science Press, Beijing. (in Chinese) [张金屯 (2011) 数量生态学. 科学出版社, 北京.]

Zhao YZ (2012) Classification and Its Floristic Ecological Geographic Distributions of Vascular Plants in Inner Mongolia. Inner Mongolia University Press, Hohhot. (in Chinese) [赵 一之 (2012) 内蒙古维管植物分类及其区系生态地理分 布. 内蒙古大学出版社, 呼和浩特.]

(责任编委: 张元明 责任编辑: 黄祥忠)

\section{附录 Supplementary Material}

\section{附录1 克氏针茅和百里香群系模式植物群落主样地影像}

Appendix 1 Photos of main plot of typical plant community of Form. Stipa krylovii and Form. Thymus mongolicus http://www.biodiversity-science.net/fileup/PDF/2017330-1.pdf

附录2 模式植物群落环境信息、物种及样地数据

Appendix 2 Environmental information, species and quadrat data of the typical plant communities http://www.biodiversity-science.net/fileup/PDF/2017330-2.xls 
高趁光, 郭柯, 乔鲜果, 陆帅志, 刘长成, 侯东杰, 王孜. 草原模式植物群落监测方法应用样例. 生物多样性, 2018, 26 (3): 266-273.

http://www.biodiversity-science.net/CN/10.17520/biods.2017330

附录1 克氏针茅和百里香群系模式植物群落主样地影像

Appendix 1 Photos of main plot of typical plant community of Form. Stipa krylovii and Form. Thymus mongolicus

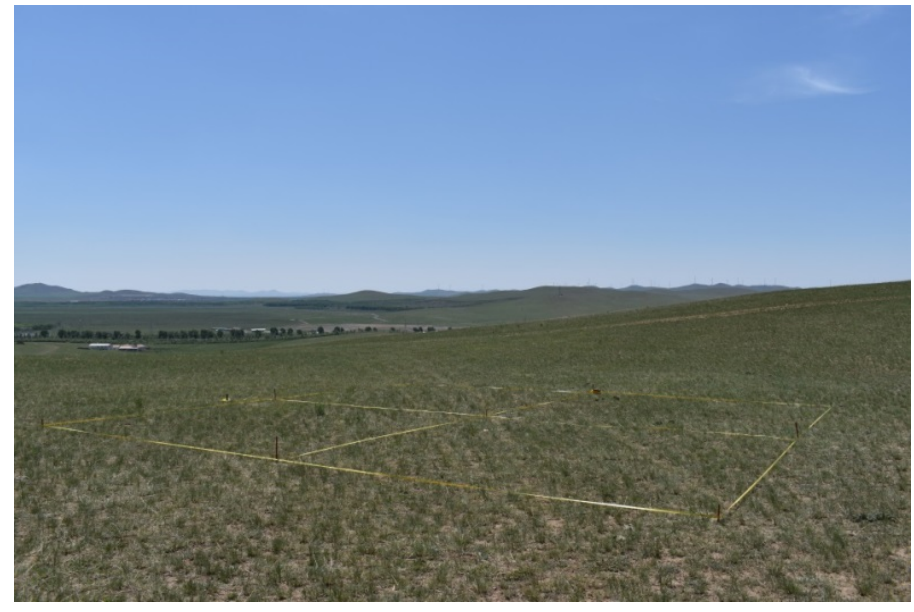

克氏针茅群系模式植物群落主样地影像

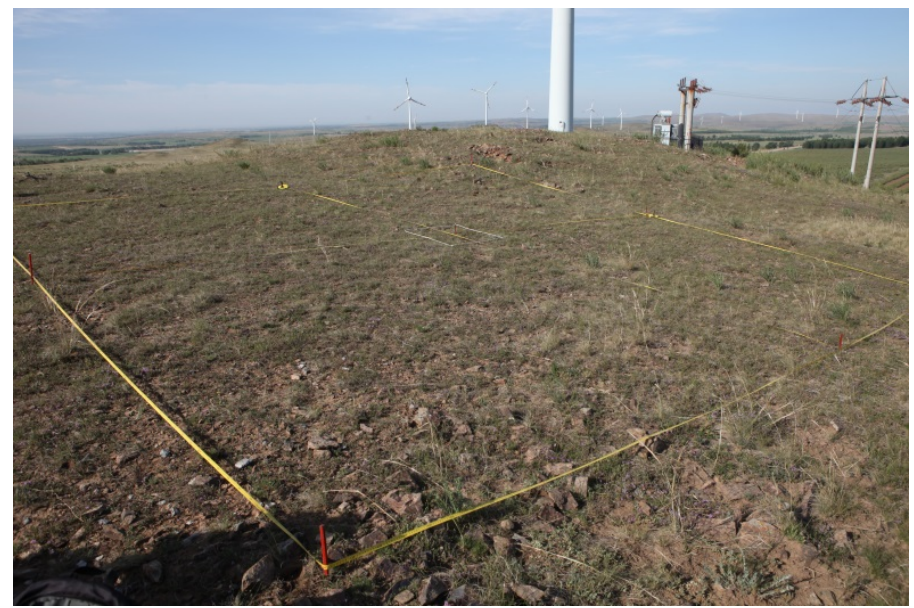

百里香群系模式植物群落主样地影像 